\title{
Widening the Field of Indication of Conservative Management of Unruptured Tubal Pregnancy in Low Resources Settings: Lessons Learnt from 10-year Experience in Three University Teaching Hospitals in Yaoundé (Cameroon)
}

\author{
Mve Koh Valere ${ }^{1,}$, Essiben Felix ${ }^{1}$, Essome Henri ${ }^{2}$, Dang Atanga Danielle ${ }^{2}$, Mbu Enow Robinson ${ }^{1}$ \\ ${ }^{1}$ Faculty of Medicine and Biomedical Sciences, University of Yaoundé I, Yaoundé, Cameroon \\ ${ }^{2}$ Faculty of Medicine and Pharmaceutical Sciences, University of Douala, Douala, Cameroon
}

Email address:

vmvekoh@yahoo.com (M. K. Valere), essibenx@yahoo.fr (E. Felix), essometocky@yahoo.com (E. Henri),

dang_danielle@yahoo.com (D. A. Danielle),robinsonmbu@gmail.com (M. E. Robinson)

${ }^{*}$ Corresponding author

\section{To cite this article:}

Mve Koh Valere, Essiben Felix, Essome Henri, Dang Atanga Danielle, Mbu Enow Robinson. Widening the Field of Indication of Conservative Management of Unruptured Tubal Pregnancy in Low Resources Settings. Lessons Learnt from 10-year Experience in Three University Teaching Hospitals in Yaoundé (Cameroon). Journal of Gynecology and Obstetrics. Vol. 7, No. 3, 2019 , pp. 60-67. doi: $10.11648 /$ j.jgo.20190703.11

Received: March 17, 2019; Accepted: April 25, 2019; Published: May 23, 2019

\begin{abstract}
Ectopic pregnancy is the leading cause of maternal mortality in the first trimester. When a patient is admitted before rupture, organ-preserving management which keeps a higher fertility rate than ablative surgery can be done. The incidence of Unruptured Ectopic Pregnancy (UTP) on admission is unknown. In the study facilities, methotrexate treatment was given to most of UTP regardless of Fernandez score. The aim of this study was therefore to assess the lessons learnt from that experience. Methods: It was a cross sectional study over a 10 years period, conducted in four university teaching hospitals affiliated to the University of Yaoundé I, Cameroon. Included patients were managed either by therapeutic abstention, single or multidose intra muscular MTX. Onset of clinical acute abdomen was the only indication of failure of conservative management and prompted emergency laparotomy. Results: We included 153 UTP cases. The incidence of UTP on admission was $0.46 \%$, the mean age $28.4 \pm 4.9,88.2 \%$ were admitted at a gestational age $<9$ weeks, $19 \%$ had no pelvic pain. Medical treatment by MTX success rate was $81.7 \%$ but was not related to mono or multiple-dose ( $\mathrm{p}=0.87$ ), the success rate when $\beta$ hCG value was $\geq 10000 \mathrm{mIU} / \mathrm{ml}$ was $63.3 \%$ ( $\mathrm{p}=0.004)$. When Fernandez score was $\geq 13,21 / 25(84 \%)$ were still successful including $3 / 7$ with cardiac activity. $(\mathrm{p}=0.007)$. Conclusions: The incidence of UTP on admission is approximately $1 / 10^{\text {th }}$ of all EP. Some UTP patients should be given MTX treatment opportunity even when Fernandez score recommends surgical management.
\end{abstract}

Keywords: Unruptured Ectopic Pregnancy, Widen Indication, Acute Abdomen

\section{Introduction}

Ectopic pregnancy (EP) defined as the implantation of the fertilized ovum outside of the uterine cavity [1] is a lifethreatening gynecological emergency with a risk of death 10 times higher than death after vaginal delivery and 50 times more than induced abortion [2]. It is the leading cause of maternal mortality in the first trimester accounting for $10 \%$ $15 \%$ of all maternal deaths [3]. EP is indeed the most frequent cause of first trimester maternal death in developed countries and in sub-Saharan Africa [4]. The maternal mortality rate due to its complications increased from $2.8 \%$ in 2001-2003 to 4.2\% 2004-2006 in France, and it was 6\% in the USA [5-6]. The mortality rate in a study in Cameroon was $12.5 \%$, three times higher than in France and was the 
third maternal mortality cause [7], and, EP can lead to lower chance of conception when compared to those who had miscarriage [8]. More than $95 \%$ of EPs occur in the fallopian tubes. [9]. The majority of patients are admitted late after rupture and hemodynamic instability in developing countries [10]. Surgery is then the most appropriate treatment and is usually an ablative surgery like partial or total salpingectomy, but after surgical management, $30 \%$ of EP cases won't be able to have another pregnancy and 15 to $30 \%$ may experience another episode of EP [11].

When a patient is admitted before rupture, organpreserving management like Methotrexate (MTX) administration, the first option for medical therapy can be given, avoiding the rupture of the concerned tube when successful, and keeping potential fertility. Organ-preserving management keeps indeed a higher fertility rate than ablative surgery. [12]. This is an important advantage as some of EP are suffering from infertility, an established risk of EP and cases of tubal re-permeability after MTX have been described [12-13].

The incidence of ectopic pregnancy is approximately 1.5 to $2 \%$ of all pregnancies [14], but the incidence of Unruptured Ectopic Pregnancy (UTP) on admission is unknown in our milieu. Systematic medical treatment had been applied to cases of UTP in some study facilities, regardless of the Fernandez score, with capability of prompt surgical take-over in case of rupture. The aim of this study was therefore to assess the lessons learnt from that experience, mainly, the profile of EP patient admitted before rupture and the relation between Fernandez score value and MTX treatment success in low resources settings.

\section{Methods}

It was a cross sectional study over a 10 years period, from January $1^{\text {st }} 2006$ to of December $31^{\text {st }} 2015$. The study was conducted over a four months period, from the first of January to April $30^{\text {th }}$ 2016. This study took place in the services of gynecology and obstetrics of four university teaching hospitals affiliated to the University of Yaoundé I, namely, the University Teaching Hospital, the GynecoObstetric and Pediatric Hospital, the Central Hospital and the General Hospital, all of them in Yaoundé, the capital city of Cameroon, a sub-Saharan African country in the gulf of Guinee with a population of 25 million. They are the only ones conducting conservative medical management of unruptured tubal pregnancy (UTP). We included all files of women hospitalized for UTP, diagnosed through both serum $\beta-h C G>10 \mathrm{ml} / \mathrm{IU}$ and pelvic or vaginal ultrasound without the presence of intrauterine pregnancy and the presence or not of a tubal sac or embryo, with or without cardiac activity, managed by methotrexate injection or expectant management regardless of $\beta$-hCG value with hemodynamic stability on admission. Files without ultrasound and $\beta$-hCG results before admission, serial $\beta$-hCG after admission and management by
MTX, clinical outcome (laparotomy or not) and discharge note were excluded, so were cases of UTP with the absolute contra-indication below: unstable hemodynamic state, contra indications to MTX: (breast feeding, immunodeficiency, ASAT or ALAT values twice higher than normal, kidney failure, thrombopenia $\left(<100000 / \mathrm{mm}^{3}\right)$, leucopenia $(<2000$ $\left./ \mathrm{mm}^{3}\right)$, hemoglobin concentration $<11 \mathrm{~g} / \mathrm{dl}$. We also excluded files without surgical findings of laparotomy in case of rupture of the previously unruptured tubal pregnancy and non-tubal extra-uterine pregnancies.

Because of the difficulties to assess progesteronemia, the evaluation of Fernandez score was done assuming a maximum value of $\mathrm{P}>10 \mathrm{ng} / \mathrm{ml}$. All the diagnosed patients were hospitalized and managed there until discharge. Full blood count, liver function test and blood type and Rh factor were done prior to the beginning of MTX treatment.

Expectant management was done in some of the cases ( $\beta$ hCG value $<500 \mathrm{IU} / \mathrm{ml}$, but monodose was given on day one of admission $1 \mathrm{mg} / \mathrm{kg}$ intra muscularly, two protocols of multi-dose were used, MTX $1 \mathrm{mg} / \mathrm{kg}$ day 1,3 and 5 , or $100 \mathrm{mg}$ intra muscularly on day 1,3 and 5 when they were cardiac activity, but in some cases, the choice of protocol was physician dependent. Successful outcome designated dropping of serial $\beta$-hCG after MTX treatment or watchful waiting (medical abstention), discharge without acute abdomen and final $\beta$-hCG value $<10 \mathrm{UI} / \mathrm{ml}$, during serial outdoor monitoring. Onset of clinical acute abdomen (rebound tenderness) was the only indication of failure of conservative management, and failure was confirmed by laparotomic rupture tubal pregnancy after at least one intra muscular injection of a total dose of $1 \mathrm{mg} / \mathrm{kg}$ MTX. All the rupture cases were surgically managed in the same health facilities.

The minimum sample size was 35 according to Lorentz formula. The data of interest were sociodemographic, (maternal age, occupation, marital status, ethnicity), contributing gynecological and obstetrical past history (Gravidity, parity, risk factors of UTP, the clinical manifestations on admission (referral case or not, gestational age, clinical signs on admission), para-clinical imaging and biological assessment results, (Pelvic/endovaginal ultrasound $\beta$-hCG values), therapeutic management and maternal outcome.

Data collected were processed by Cs Pro 6.1 and SPSS 20.0. Differences in baseline characteristics between different modalities were assessed by $\mathrm{X}^{2}$, the threshold of significance was $P \leq 0.05$. This study received the ethical clearance of the ethical committee of the university of Douala in Cameroon and the authorization of the directors of the four University teaching Hospitals.

\section{Results}

We included 153 cases of UTP corresponding to inclusion criteria. There was no fatal outcome. 
Table 1. Incidence of UTP on admission.

\begin{tabular}{llll}
\hline Hospital & Number of UTP & Total number of deliveries & Frequency (\%) \\
\hline GOPH & 163 & 25884 & 0.60 \\
UTH & 156 & 18996 & 0.80 \\
CH & 62 & 39060 & 0.10 \\
GHD & 45 & 7777 & 0.57 \\
Total & 426 & 91717 & 0.46 \\
\hline
\end{tabular}

GOPH: Gyneco-Obstetric and Pediatric Hospital

UTH: University Teaching hospital

CH: Central Hospital

GHD: General Hospital

The incidence of UTP was $0.46 \%$ (4, 6 cases for 1000 births).

Table 2. Sociodemographic and clinical parameters distribution of UTP.

\begin{tabular}{|c|c|c|}
\hline Variables & $\mathbf{n}$ & Percentage (\%) \\
\hline \multicolumn{3}{|l|}{ Ages (years) } \\
\hline$[16-20]$ & 5 & 3.2 \\
\hline [20-25] & 45 & 29.4 \\
\hline$[25-30]$ & 57 & 37.2 \\
\hline$[30-35]$ & 32 & 20.9 \\
\hline$[35-40]$ & 12 & 8 \\
\hline$[40-45]$ & 2 & 1.3 \\
\hline \multicolumn{3}{|l|}{ Marital status } \\
\hline Married & 57 & 27 \\
\hline Single & 96 & 63 \\
\hline \multicolumn{3}{|l|}{ Gestity } \\
\hline 1 & 29 & 19 \\
\hline $2-3$ & 69 & 45 \\
\hline 4 & 41 & 27 \\
\hline$\geq 5$ & 14 & 9 \\
\hline \multicolumn{3}{|l|}{ Parity } \\
\hline 0 & 62 & 41 \\
\hline 1 & 43 & 28 \\
\hline $2-3$ & 39 & 25 \\
\hline 4 & 9 & 6 \\
\hline Mode of admission & 108 & 70.6 \\
\hline \multicolumn{3}{|l|}{ Going directly from home to the final management center } \\
\hline Referred from another lower category health center & 45 & 29.4 \\
\hline \multicolumn{3}{|l|}{ Gestational age on admission (weeks) } \\
\hline No identified amenorrhea & 4 & 2.6 \\
\hline$<9$ & 135 & 88.2 \\
\hline$[9-16]$ & 13 & 8.5 \\
\hline$\geq 16$ & 1 & 0.7 \\
\hline \multicolumn{3}{|l|}{ Symptoms } \\
\hline Amenorrhea & 149 & 97.4 \\
\hline Pelvic pain & 124 & 81 \\
\hline Metrorrhagia & 96 & 62.7 \\
\hline \multicolumn{3}{|l|}{ Gestational sac tubal position } \\
\hline Right tube & 96 & 62.7 \\
\hline Left tube & 57 & 37.3 \\
\hline
\end{tabular}

The mean age was $28.4 \pm 4.9$ years (minimum 18 and maximum 45 years). The age group [25-30] was the most frequent and [20-35] represented $87.7 \%$ of the sample. Amenorrhea was present, but pain and menorrhagia were absent on 18 and $36.3 \%$ respectively. Two third were single, gestity $2-3$ represented $45 \%$, parity 0 and $1,69 \%, 71 \%$ chose at first intention university teaching hospital, $88.2 \%$ were admitted at a gestational age $<9$ completed weeks, $97.4 \%$ had amenorrhea and the right tube was the mostly affected $(62.7 \%)$.
Table 3. Management and outcome of UTP.

\begin{tabular}{lll}
\hline Modalities & $\mathbf{n = 1 5 3}$ & Frequency (\%) \\
\hline Management & & \\
Expectant management & 4 & 2.6 \\
Medical treatment by MTX & 149 & 97.4 \\
Evolution of UTP & & \\
Success of treatment & 125 & 81.7 \\
Rupture of UTP & 28 & 18.3 \\
\hline
\end{tabular}

Medical treatment by MTX was indicated in $97.4 \%$ of cases with a success rate of $81.7 \%$. 
63 Mve Koh Valere et al:: Widening the Field of Indication of Conservative Management of Unruptured Tubal Pregnancy in Low Resources Settings. Lessons Learnt from 10-year Experience in Three University Teaching Hospitals in Yaoundé (Cameroon)

Table 4. UTP outcome according to MTX protocol.

\begin{tabular}{lll}
\hline MTX protocol & Single-dose n (\%) & Multi-dose ( $\geq \mathbf{2}) \mathbf{n}(\mathbf{\%})$ \\
\hline Success of treatment & $59(79.7)$ & $62(82.7)$ \\
Rupture of UTP & $15(20.3)$ & $13(17.3)$ \\
Total $\mathrm{P}=0.87$ & $74(100)$ & $75(100)$ \\
\hline
\end{tabular}

There was no statistically significant difference between single (success rate $79.9 \%$ ) and multi-dose (success rate $82.7 \%$ ) $\mathrm{p}=0.87$.

Table 5. UTP outcome according to initial $\beta$-hCG value.

\begin{tabular}{lllll}
\hline $\boldsymbol{\beta}$-hCG mUI/ml & $<\mathbf{1 0 0 0} \mathbf{n}(\mathbf{\%})$ & {$[\mathbf{1 0 0 0 - 5 0 0 0 ]} \mathbf{n}(\mathbf{\%})$} & $\mathbf{[ 5 0 0 0 - 1 0 0 0 0 ]} \mathbf{n}(\mathbf{\%})$ & $\geq 1 \mathbf{1 0 0 0 0} \mathbf{n}(\mathbf{\%})$ \\
\hline Success of treatment & $34(97.1)$ & $54(80.6)$ & $18(85.7)$ & $19(63.3)$ \\
Rupture of UTP & $1(2.1)$ & $13(19.4)$ & $3(14.3)$ & $11(36.7)$ \\
Total & $35(100)$ & $67(100)$ & $21(100)$ & $30(100)$ \\
$\mathrm{X}^{2}$ & 7.23 & 0.097 & 3.318 & 8.419 \\
$\mathrm{P}$ & 0.07 & 0.756 & 0.069 & 0.004 \\
\hline
\end{tabular}

The rate of success decreased as initial $\beta$-hCG value increased, and the success rate was $63.3 \%$ even when initial $\beta$-hCG was $>10000 \mathrm{mIU} / \mathrm{ml}(\mathrm{p}=0.004)$

Table 6. UTP outcome according to Fernandez score on admission.

\begin{tabular}{llll}
\hline FERNANDEZ SCORE & $<\mathbf{9} \mathbf{~ ( \% )}$ & $\mathbf{9 - 1 2} \mathbf{n}(\mathbf{\%})$ & $\geq \mathbf{1 3} \mathbf{n}(\mathbf{\%})$ \\
\hline Success of treatment & $1(100)$ & $103(81.1)$ & $21(84)$ \\
Rupture of UTP & 0 & $24(18.9)$ & $4(16)$ \\
$\mathrm{X}^{2}$ & 0.225 & 0.178 & 0.106 \\
$\mathrm{P}$ & 0.635 & 0.673 & 0.745 \\
Total & 1 & 127 & 25 \\
\hline
\end{tabular}

The success rate was decreasing as Fernandez score was increasing. A Fernandez score recommending surgical management of UTP still had a successful rate of $84 \%$ after medical treatment by MTX.

Table 7. UTP outcome according to MTX protocol and $\beta-h C G$ value on admission.

\begin{tabular}{|c|c|c|c|c|}
\hline Taux de ( $\beta$-hCG mUI/ml) & $<1000 \mathrm{n}(\%)$ & {$[1000-5000]$ n (\%) } & {$[5000-10000]$ n (\%) } & $\geq 10000 \mathrm{n}(\%)$ \\
\hline \multicolumn{5}{|l|}{ MTX 1} \\
\hline Success of treatment & $24(96)$ & $24(75)$ & $8(80)$ & $3(43)$ \\
\hline Rupture of UTP & $1(4)$ & $8(25)$ & $2(20)$ & $4(57)$ \\
\hline Total & $25(100)$ & $32(100)$ & $10(100)$ & $7(100)$ \\
\hline \multicolumn{5}{|l|}{ MTX 2} \\
\hline Success of treatment & $8(100)$ & $28(85)$ & $10(91)$ & $16(69.6)$ \\
\hline Rupture of UTP & 0 & $5(15)$ & $1(9)$ & $7(30.4)$ \\
\hline Total & $8(100)$ & $33(100)$ & $11(100)$ & $23(100)$ \\
\hline
\end{tabular}

MTX1: Single-dose protocol

MTX2: Multi-dose protocol

The overall success rate when $\beta$-hCG was $\geq 10000 \mathrm{miu} / \mathrm{mL}$ was $63.3 \%(19 / 30)$.

Table 8. UTP outcome according ultrasonographic findings.

\begin{tabular}{lllll}
\hline Evolution n=153 & Cardiac activity present & Hydrosalpinx & Pyosalpinx & Salpingitis \\
\hline Success of treatment & $3(43 \%)$ & 5 & 1 & 1 \\
Rupture of UTP & $4(57 \%)$ & 0 & 0 & 0 \\
$\mathrm{X}^{2}$ & 7.402 & & & \\
$\mathrm{P}$ & 0.007 & 3.3 & 0.7 & 0.7 \\
Frequency (\%) & 4.6 & & & \\
\hline
\end{tabular}

Cardiac activity was present in $7 / 153$ cases (4.6\%) all treated by multidose, and the success rate of $43 \%$ was statistically significant 

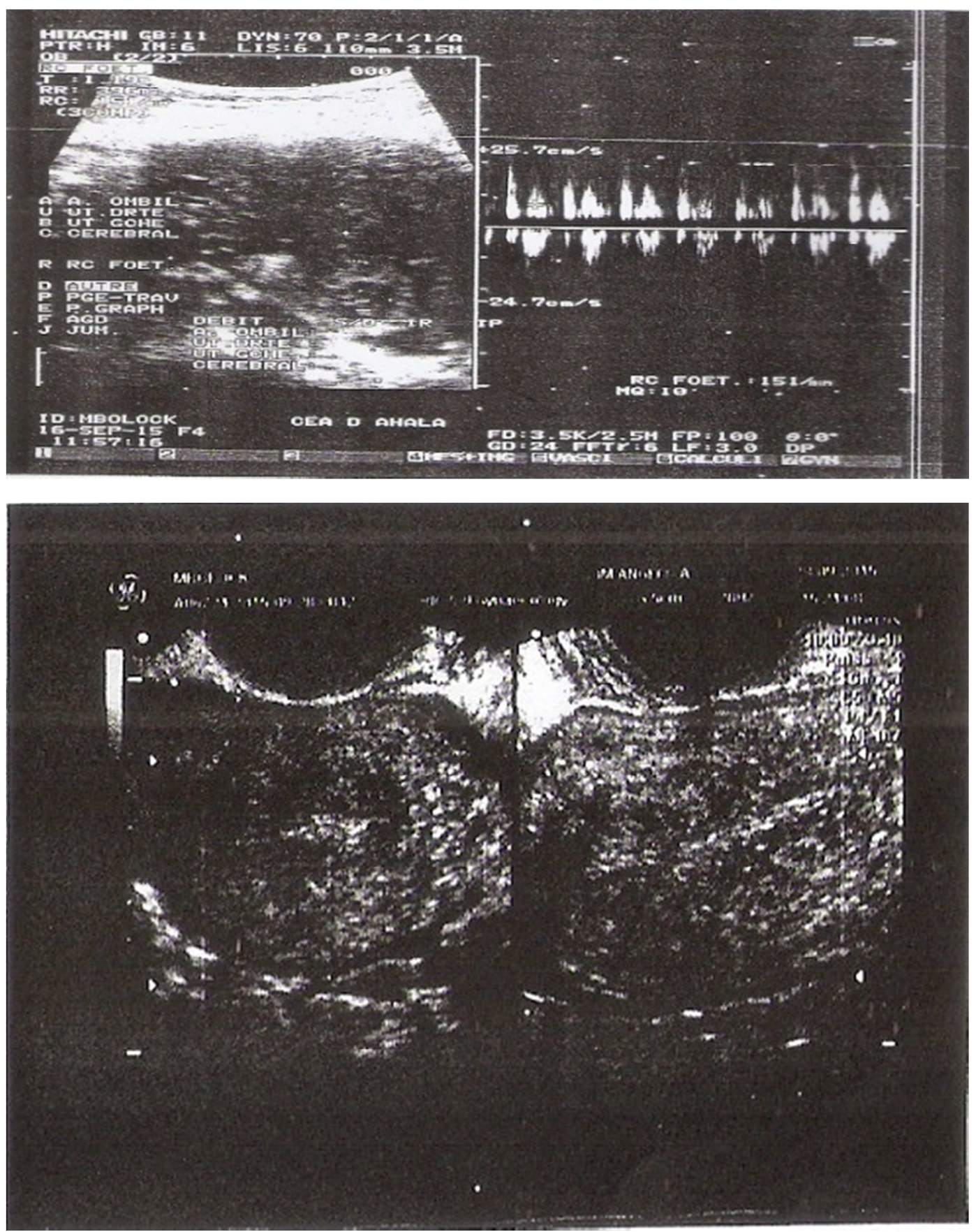

Figure 1. One of the cases of successful treatment with cardiac activity.

\section{Discussion}

\subsection{Incidence of $U T P$}

The incidence of ectopic pregnancy is approximately 1.5 to $2 \%$ of all pregnancies [14]. The incidence in the western world ranges between $1-3 \%$ of all pregnancies [15], and was $4.2 \%$ in a Cameroonian study conducted in the same city [16]. The incidence of UTP ranged from 0.1 to 0.8 from one hospital to another and the average was $0.46 \%$ in this study over a ten-year period (Table 1). The incidence of UTP on admission is poorly assessed in the recent literature. That incidence was one tenth $\left(1 / 10^{\text {th }}\right)$ of the frequency of all EP found in the Cameroonian study mentioned above [16]. Only one out of 10 cases of all ectopic pregnancies are admitted before tubal rupture. This shows the magnitude of sensitization to be implemented, in order to improve the awareness of early consultation in case of amenorrhea, and increase the proportion of EP admitted before rupture, so that EP patients can be given the opportunity of fertility preserving conservative management, since infertility is a well-known underlying risk factor, and to reduce the mortality related to this leading cause of maternal mortality in the first trimester [3] 


\subsection{Socio-Demographic and Clinical Data}

the majority of patients were represented by the [20-35] age range (Table 2), like found in other publications [17], probably due to the fact that it is the age of maximum pregnancy rate even in intra uterine pregnancies studies [18]. Up to $29.4 \%$ didn't chose an appropriate health facility, and were referred from another health facility, adding another delay in the management (Table 3). This was probably due to the low setting environment and ignorance, as almost all of them $(97.4 \%)$ consulted at a rather late gestational age $(\geq 9$ weeks), reducing the proportion of expectant management adopted in this study to $2.6 \%$ (4/153) of cases. (Table 3 ). Studies conducted in western world has shown indeed an earlier average gestational age at the moment of consultation. It was 7 weeks \pm 11 days in France for example. [19]

\subsection{Success Rate After MTX Protocol}

The overall success rate of this study was high $(81.3 \%$ $125 / 153)$ and success rate after MTX management was $81.2 \%$ $(121 / 149)$ (Table 3 ) as found in many studies [20, 21], but it was not statistically correlated to MTX mono or multi-dose protocol (Table 4; $\mathrm{p}=0.87$ ), although multi-dose success rate was higher than mono-dose, and this was obvious when $\beta$-hCG was $>10000 \mathrm{IU} / \mathrm{L}$ with a success rate of $16 / 23$ when monodose succeeded only on $3 / 7$ cases (Table 6 ). The success rate of MTX management of UTP varies from 72 to $95 \%$ [22-23]. A $100 \%$ success rate has already been reported [24]. The choice of the most appropriate MTX protocol is still debated. Mergenthal et al, in a prospective multicenter cohort study, among UTP cases with similar initial $\beta$-hCG levels found that, the mean rate of decline of $\beta$-hCG from day 0 to day 7 was significantly more rapid in women who received the singledose protocol compared to 2-dose protocol with no difference in success rate or time to successful resolution [25]. In a prospective randomized trial comparing the success of singledose MTX treatment versus multiple-dose MTX in patients with unruptured EP, no difference was found between the two MTX treatment regimens [26]. A recent systematic review of randomized controlled trials between 1974 and 2016 has also concluded that, the overall success rate of multiple-dose protocol was similar to the single-dose protocol and the incidence of side-effects of multiple dose protocol was significantly higher than single-dose protocol, concluding that the double-dose regimen was an efficient alternative to the single-dose protocol [27]. But some studies based on $\beta$-hCG variation has shown a better reduction with multi-dose protocol. Inal et al in a recent study found that serial $\beta$-hCG values on Day 0, 4 and 7 were statistically different between expectant management, single dose, multi-dose and the surgical intervention group [28].

The success of single-dose MTX therapy can be affected by the patient's serum $\beta$-hCG levels, positive fetal cardiac activity, the presence of a yolk sac, and the size of the ectopic mass [29]. The relation between the occurrence of rupture and $\beta$-hCG value is unknown. According to Barnhart, tubal rupture can happen at any time if $\beta$-hCG values are between
10 to $189720 \mathrm{UI} / \mathrm{L}$ [30], and Saxon added that, there was no anamnestic, clinical, biological or ultrasonic means which could permit to identify EP cases to rupture [31]. Concerning predictive factors of rupture, and according to Shaamash, a cut-off "percentage of fall" in $\beta$-hCG serum levels on D1D7 of $33 \%$ had the best sensitivity (96\%) and specificity $(85 \%)$ for predicting a successful outcome and this was outperforming any cut-off on days 1-4 and was comparable to the standard D4-D7 protocol [32]. According to Pooja, pretreatment $\beta$-hCG level of $<6000 \mathrm{mIU} / \mathrm{ml}$, adnexal mass size $<3 \mathrm{cms}$, amenorrhoea $<6$ weeks and absence of free fluid in the pelvis are predictors of a successful treatment with MTX [33].

Bonin analyzing 314 UTP rather concluded that, the main factors associated with methotrexate failure included day (D) 0, D4 and D7 hCG levels, pretherapeutic blood progesterone, hematosalpinx on D0 and pain on D7 [34].

This study considered clinical acute abdomen as the only indication of surgical management take-over, since all the UTP cases were hospitalized in close hemodynamic monitoring. From our results, not focusing on the recommended "successful "falling rate" but rather on the onset or not of clinical acute abdomen as the only event recommending surgical management probably gave a chance to cases whom might have gone through surgical management without acute abdomen, and, this might explain the success rate of $63.3 \%$ even when initial $\beta$-hCG was $>10000 \mathrm{mIU} / \mathrm{ml}$ (Table 5; $\mathrm{p}=0.004$ ), the unexpected success rate of $84 \%(21 / 25)$ in cases where the Fernandez score was $>13$ and the absence of statistical correlation between Fernandez score/management/outcome ( $p=0.74$; Table 6), including three successful treatment out of seven (3/7) UTP with cardiac activity (Table $7 \mathrm{P}=0.07$; Figure 1). This is a specific finding of this study, challenging what has been recommended so far, as long as the recommendations of Fernandez score are concerned. Whether or not considering the occurring of acute abdomen during MTX treatment of UTP as the only indication of surgical take over should be generalized still need further analytical studies.

The majority of ectopic pregnancies are admitted after rupture [35], and yet, the mortality rate is relatively low, between 2 and 4/1000 [36]. Acute abdomen occurring during hospitalization under close monitoring while administrating MTX should easily and promptly be taken care of in university teaching hospitals where this study was conducted. This leaves a ground for more daring attitude and patience in order to give optimum chance to each case as nothing can predict the occurrence or not nor the moment of rupture.

\section{Conclusion}

The incidence of UTP on admission was relatively low approximately $1 / 10^{\text {th }}$ of the incidence of all EP, the overall success rate of medical management of UTP by MTX was high even in low settings management, but was not related to MTX protocol. Some UTP patients should be given MTX treatment opportunity even when Fernandez score 
recommends surgical management. Analytical studies considering the occurrence of clinical acute abdomen as the sole signal of UTP medical treatment failure should be conducted to reassess the full potential of medical management of UTP by MTX

\section{Contribution of Authors}

MVE KOH Valère did the study design and wrote the article, Dang Atanga Danielle collected the data, Felix Essiben, Essome Henri and Mbu Robinson reviewed and provided critical comments and suggestions for the manuscript.

\section{Limitations}

This study didn't analyze specifically each EP clinical data and adopted protocol

\section{Competing Interests}

All the authors do not have any possible conflicts of interest and declare that they have no competing interests; this work was not sponsored by any organization and was self-financed.

\section{Acknowledgements}

We thank all the team of the three health facilities including the managers who made this study possible.

\section{References}

[1] Tindall VR. Ectopic pregnancy. In: Jeffcoate's Principles of Gynaecology, 7th edition, Oxford, Butterworth-heinemann Ltd.; 1996: 212-225.

[2] Cunningham, Mac Donald, Grant, Levena, Gilstrap. Ectopic pregnancy. William Obstetrics 19th edition. USA: Applengton \& Hance; 1993. p. 691-715.

[3] Sara HG, Uzelac PS. Early pregnancy risks. In: DeCherney AH, Nathan L, Goodwin MT, Laufer N, editors. Current Diagnosis and Treatment: Obstetrics and Gynecology. 10th ed. Columbus (OH): McGraw-Hill; 2007: 259-272.

[4] Thonneau P, Hijazi Y, Goyaux N, Calvez T and Keita N. Ectopic pregnancy in Conakry, Guinea. Bull World Health Organ. 2002; 80: 365-70.

[5] Saucedo M, Deneux-Tharaux C et Bouvier-Colle $\mathrm{MH}$. Épidémiologie des morts maternelles en France 2001-2006. BEH 2-3, 19 janvier 2010: 10-14.

[6] Creanga AA, Shapiro-Mendoza CK, Bish CL, Zane S, Berg $\mathrm{CJ}$ and Callaghan WM. Trends in ectopic pregnancy mortality in the United States, 1980-2007. Obstet Gynecol. 2011; 117: 837-43.

[7] Tebeu PM, Halle Ekane G, Da Itambi, Mbu Enow R, Mawanba Y and Fomulu NJ: Maternal mortality in Cameroon: A university hospital report. Pan African Medical Journal, 2015, 21: 16. doi: 10.11604/pamj.2015.21.16.3912.
[8] Bhattacharya S, McLernon DJ, Lee AJ and Bhattacharya S. Reproductive Outcomes Following Ectopic Pregnancy: Register-Based Retrospective Cohort Study. PLoS Med. 2012; 9 (6): e1001243.

[9] Chen XL, Chen ZR, Cao ZL, Han K, Tong YW, Xiang XH et al. The 100 most cited articles in ectopic pregnancy: a bibliometric analysis. SpringerPlus. 2016; 5: 1815. DOI 10.1186/s40064-016-3503-8.

[10] Panti A, Ikechukwu NE, lukman OO, Yakubu A, Egondu SC and Tanko BA. Ectopic pregnancy at Usmanu Danfodiyo University Teaching Hospital, Sokoto: a ten-year review. Ann Niger Med. 2012; 6 (2): 87-91.

[11] Lansac Lecomte Maret. Gynécologie pour le praticien. 7e ed. Paris: Masson 2007. 161-163.

[12] Taran F-A, Kagan K-O, Hübner M, Hoopmann M, Wallwiener D and Brucker S. The Diagnosis and Treatment of Ectopic Pregnancy. Dtsch Arztebl Int. 2015; 112: 693-704.

[13] Grau EM, Checa Vizca ' 1no, 'MA, Oliveira M, Lleberia Juanos J, Collado RC, and Yolanda Canet Estevez Y. The Value of Hysterosalpingography following Medical Treatment with Methotrexate for Ectopic Pregnancy. Obstetrics and Gynecology International. Vol 2011, 5 pages. doi: $10.1155 / 2011 / 547946$.

[14] Chang J, Elam-Evans LD, Berg CJ, Herndon J, Flowers L, Seed KA et al. Pregnancy-related mortality surveillance United States, 1991-1999. MMWR SurveillSumm 2003; 52: $1-8$.

[15] Farquhar CM. Ectopic pregnancy. Lancet. 2005; 366 (9485): 583-91.

[16] Foumane P, Mboudou ET, Mbakop Ndingue S, Dohbit JS, Belinga $\mathrm{E}$ and Doh A. S. La place du traitement peu ou non invasif dans la prise en charge de la grossesse extra-utérine à l'hôpital gynéco-obstétrique et pédiatrique de Yaoundé: Une analyse rétrospective sur cinq ans. Clin Mother Child Health. 2010; Vol 7, $\mathrm{N}^{\circ}$ 1: 1201-1204.

[17] Osaheni L Lawani, Okechukwu B Anozie and Ezeonu PO. Ectopic pregnancy: a life-threatening gynecological emergency. International Journal of Women's Health. 2013; 5: $515-521$.

[18] Mve Koh V, Belinga E, Engbang Ndamba JP and Kasia JM. Macrosomic Newborn Anthropometric Parameters and the Mode of Delivery. Gynecol Obstet (Sunnyvale) 2018, 8: 10.

[19] Gervaise A, Fernandez H. Le méthotrexate dans le traitement médical des grossesses extra-utérine non rompues. Etude prospective: injection intra-musculaire versus injection in situ sous contrôle échographique. J Gynecol Obstet Biol Reprod 2003; 32: 420-425.

[20] Shaamash AH, Alshahrani MS, Awadalla NJ and Hakami HW Falling in serum $\beta$ human chorionic gonadotropin levels between days 1 and 7 as a new protocol to predict successful single-dose of methotrexate therapy for ectopic pregnancy. Middle East Fertility Society Journal. 2015; 20: 159-164.

[21] Thia E W H, Loi K, Wang J J and Siow A. Methotrexate treatment for ectopic pregnancy at the KK Women's and Children's Hospital, Singapore. Singapore Med J. 2009; 50 (11): 1058-61. 
67 Mve Koh Valere et al:: Widening the Field of Indication of Conservative Management of Unruptured Tubal Pregnancy in Low Resources Settings. Lessons Learnt from 10-year Experience in Three University Teaching Hospitals in Yaoundé (Cameroon)

[22] Sendy F, AlShehri E, Alajmi A, Bamanie E, Appani S and Taghreed Shams. Failure Rate of Single Dose Methotrexate in Managment of Ectopic Pregnancy. Obstetrics and Gynecology International; Vol 2015, Article 5 pages. http://dx.doi.org/10.1155/2015/902426 Accessed December $10,2018$.

[23] Lipscomb GH, Givens VM, Meyer NL, Bran D, and Zinberg S. Comparison of multidose and single-dose methotrexate protocols for the treatment of ectopic pregnancy. Am J Obstet Gynecol. 2005; vol. 192, no. 6, pp. 1844-1847.

[24] Skubisz M, Dutton P, Duncan WC, Horne AW and Tong S. Using a decline in serum hCG between days $0-4$ to predict ectopic pregnancy treatment success after single-dose methotrexate: a retrospective cohort study. BMC Pregnancy and Childbirth. 2013; vol. 13 (1): 30 Doi: 10.1186/1471-239313-30.

[25] Mergenthal MC, Senapati S, Zee J, Taylor LA, Whittaker PG, Takacs $\mathrm{P}$ et al. Medical management of ectopic pregnancy with single-dose and 2-dose methotrexate protocols: human chorionic gonadotropin trends and patient outcomes. Am J Obstet Gynecol. 2016; 215: 590. e1-5.

[26] Guvendag Guven ES, Dilbaz S and Dilbaz B. Comparison of single and multiple dose methotrexate therapy for unruptured tubal ectopic pregnancy: a prospective randomized study. Acta Obstet Gynecol Scand. 2010; 89: 889-895.

[27] Yang C, Cai J, Yuhong Geng YH and Gao Y. Multiple-dose and double-dose versus single-dose administration of methotrexate for the treatment of ectopic pregnancy: a systematic review and meta-analysis. Reprod. Biomed. Online. 2017; 383-391.

[28] Inal ZO and Inal HA. Comparison of Four Methods of Treating Ectopic Pregnancy: A Retrospective Cohort Study. Geburtshilfe Frauenheilkd. 2018 Jan; 78 (1): 70-77.

[29] Yıldırım A, Cirık DA, Altay M and Gelison Q. Early prediction for the requirement of second or third dose methotrexate in women with ectopic pregnancy, treated with single-dose regimen. Arch Gynecol Obstet. 2015; 291 (6): $1327-1332$

[30] Barnhart K, Mennuti MT, Benjamin I, Jacobson S, Goodman $\mathrm{D}$ and Coutifaris C. Prompt diagnosis of ectopic pregnancy in an emergency department setting. Obstet Gynecol. 1994 Dec; 84 (6): 1010-5.

[31] Saxon D, Falcone T, Mascha EJ, Marino T, Yao M and Tulandi TA. Study of ruptured tubal ectopic pregnancy. Obstet Gynecol. 1997 Jul; 90 (1): 46-9.

[32] Shaamash AH, Alshahrani MS, Awadalla NJ and Hakami HW. Falling in serum $\beta$ human chorionic gonadotropin levels between days 1 and 7 as a new protocol to predict successful single-dose of methotrexate therapy for ectopic pregnancy. Middle East Fertility Society Journal. 2015; 20: 159-164.

[33] Pooja Rajesh Vaswani. Predictors of Success of Medical Management of Ectopic Pregnancy in a Tertiary Care Hospital in United Arab Emirates. Journal of Clinical and Diagnostic Research. 2014; Aug, Vol-8 (8): OC04-OC08.

[34] Bonin L, Pedreiro C, Moret S, Chene G, Gaucherand P and Lamblin G. Predictive factors for the methotrexate treatment outcome in ectopic pregnancy: A comparative study of 400 cases. Eur J Obstet Gynecol Reprod Biol. Jan 2017; Vol 208: $23-30$.

[35] Ubung Iklaki C, Ife Emechebe C, Charles Obinna Njoku C and Ago B. Review of Ectopic Pregnancy as a Cause of Maternal Morbidity and Mortality in a Developing Country. IOSR-Journal of Dental and Medical Sciences (IOSR-JDMS). 2015; Vol 14; 8 Ver. VI Aug: 86-91.

[36] Schneider J, Berger CJ and Cattell C. Maternal mortality due to ectopic pregnancy. A review of 102 deaths. Obstet Gynecol. 1977 May; 49 (5): 557-61. 